ISSN: 2146-3042

DOI: $10.25095 /$ mufad.673738

\title{
Entelektüel Sermaye Etkinliğinin Veri Zarflama Analizi ile Değerlendirilmesi: BİST Teknoloji Şirketlerine Yönelik Bir Araştırma*
}

Neilan SOYLU *

\section{$\ddot{O Z E T}$}

Hızla değișen teknoloji çağında işletmelerin sahip oldukları kaynakların katma değer yaratarak gelir ve kara dönüștürme süreci, büyük ölçüde insan sermayesi, yapısal sermaye ve müşteri sermayesi gibi entelektüel sermaye bileșenlerinin etkin kullanımı ve yönetimine bağlı olmaktadır. Bu çalıșmada, Borsa İstanbul'da ișlem gören teknoloji sektörü firmalarının entelektüel sermaye bileşenlerinin gelir ve kar yaratma sürecinde etkinlikleri veri zarflama analizi ile değerlendirilmiştir. Çalışma kapsamına alınan 14 işletmenin 2017 ve 2018 ylllarına ait verileri kullanılarak entelektüel sermaye bileşenleri ile ilişsilendirilen uygun girdi ve çıktılar belirlenmiş, daha sonra CCR (Charnes-Cooper-Rhodes) ve BCC (Banker-Charnes-Cooper) modelleri kullanılarak işletmelerin göreli toplam etkinlikleri, saf teknik etkinlikleri ve ölçek etkinlikleri hesaplanmıștır. Yapılan analiz sonucunda hem CCR hem BCC modeline göre, işletmelerin 2018 yılında önceki yıla göre entelektüel sermaye bileşenlerini daha etkin kullandıkları tespit edilmiştir.

Anahtar Kelimeler: Entelektüel Sermaye, Veri Zarflama Analizi, Etkinlik

JEL Sinıflandırması: C61, E22, G30

\section{Evaluation of Intellectual Capital Efficiency With Data Envelopment Analysis: A} Research On BIST Technology Companies

\section{ABSTRACT}

In rapidly changing technology era, the process of transforming the resources of companies into income and profit by creating added value depends to a great extent on the efficient use and management of intellectual capital components such as humancapital, structural capital and customer capital. In this study, the efficiency of the intellectual capital components of the technology sector companies traded on Borsa Istanbul in the process of generating income and profit was evaluated with data envelopment analysis. Based on 2017 and 2018 data, appropriate inputs and outputs related to intellectual capital components of the 14 companies included in the study were determined; subsequently, relative technical efficiency, pure technical efficiency and scale efficiency of the companies were calculated by using CCR (Charnes-Cooper-Rhodes) and BCC (Banker-Charnes-Cooper) models. According to both CCR and BCC model, the results of the analysis revealed that companies used intellectual capital components more efficiently in 2018 compared to the previous year,

Keywords: : Intellectual Capital, Data Envelopment Analysis, Efficiency

Jel Classification: C61, E22, G30

* Makale Gönderim Tarihi: 02.07.2019, Makale Kabul Tarihi: 06.08.2019, Makale Türü: Araştırma Makalesi

* Dr. Öğretim Üyesi, Karabük Üniversitesi, İşletme Fakültesi, neilansoylu@karabuk.edu.tr, ORCID ID: 00000002-1258-2701 


\section{GİRIŞ}

Sanayi toplumunda ekonomik büyümenin ve toplumsal gelişmenin temel kaynağ 1 olarak maddi varlıklar yeterli kabul edilirken, bilgi ekonomisine geçiş ile beraber şirketlerin varlıklarını sürdürebilmeleri, rekabet avantajı sağlayarak büyümeleri ve katma değer yaratmalarının, bilgiye dayalı, entelektüel varlıklara bağlı olduğu söylenebilir. Ancak, hızla değişen teknoloji çağında bilgi kaynaklarının değere dönüşerek firma performansını artırması, bu kaynakların sürekli geliştirilmesi ve güncellenmesi, paylaşılması ve etkin kullanılması ile ilgilidir. İşletmenin sahip olduğu maddi varlıkların ötesinde, bu değer yaratım sürecine katkısı olan kavramlar bütünü entelektüel sermaye olarak karşımıza çıkmaktadır.

Entelektüel sermaye, işletmelerin ürün ve hizmet yaratmak için kullanabilecekleri odaklanmış, organize edilmiş bir bilgi stoku olarak tanımlanabilmektedir. Ancak, bir bilgi stokunun varlığı şirketin yüksek performans göstererek rekabet üstünlüğü sağlaması için yeterli değildir; önemli olan, işletmenin sahip olduğu bilgi kaynaklarını kullanma, yönetme yeteneğidir. Diğer bir ifade ile, entelektüel sermaye, şirket içinde dağınık bulunan bilgi kümelerinin firma yararına motive ve koordine etmek ve bu sayede bilgiyi değere dönüştürebilmektir (Edvinsson ve Sullivan, 1996:357).

90’lı yıllardan itibaren entelektüel sermaye kavramı çok araştırılmış olmasına rağmen bileşenleri konusunda tam bir fikir birliğine varılamamıştır. Edvinsson ve Sullivan (1996), Edvinsson ve Malone (1997) entelektüel sermayenin iki temel bileşenden oluştuğunu öne sürmektedirler; insan sermayesi ve yapısal sermaye (entelektüel varlıklar). Bu ikili ayrımda, insan sermayesi, şirkete ve hissedarlara ait değildir ve bir süreliğine kiralanabilir; entelektüel varlıklar ise şirkete aittir. Bu nedenle, özellikle bilgi yoğun işletmelerde insan kaynağının yarattığı inovasyonları şirketin sahip olabileceği entelektüel varlıklara dönüştürerek yapısal sermayenin bir parçası haline getirmek son derece önemlidir (Edvinsson ve Sullivan, 1996:358). Benzer şekilde, 1999 yılında, Ekonomik Kalkınma ve İşbirliği Örgütü (OECD) entelektüel sermayeyi, bir işletmenin sahip olduğu yapısal (organizasyonel) sermaye ile insan sermayesi gibi maddi olmayan bileşenlerin ekonomik değeri olarak tanımlamıştır. Bontis (1998) ve Stewart (1997) gibi yazarların öncülük ettiği bir akım ise müşteri (veya ilişki) sermayesinin de bileşen olarak değerlendirildiği üçlü bir sınıflama yapmışlardır.

İnsan sermayesi kavramı, şirketin devamlılığını sürdürebilmesi için gerekli olan, sektöre özgü teknik ve operasyonel mesleki bilgi ve deneyimlerin yanı sıra çalışanların iletişim, motivasyon ve liderlik gibi bireysel bilgi, beceri ve yeteneklerinden oluşmaktadır. Dolayısıyla, insan kaynağının insan sermayesine dönüşmesi bir yandan çalışanların şirket faaliyetlerine ve misyonuna uygun olarak öğrenme, ekip çalışması, iletişimin gelişmesi gibi süreçlerde bireysel motivasyonunu ve katılımını gerektirmekte, diğer yandan da şirketi insan kaynağını geliştirmek için gayret etmesini zorunlu kılmaktadır (McGregor vd., 2004:154156). Şirketin inovasyon ve stratejik yenilikçilik potansiyelinin ortaya çıkarılması ve performansını artırarak başarıya ulaşması için insan sermayesini, bir yatırım unsuru olarak değerlendirmesi ve gelişimi için sürekli bir çaba içinde olunması gerekir (Bontis, 1998:66). Yapısal sermaye ise, şirket çalışanlarının optimum entelektüel performansa ulaşabilmeleri için sağlanan yapılar, mekanizmalar ve ortam olarak ifade edilebilir (Bontis, 1998:66). Bu kompozisyon içerisinde patentler, telif hakları, ticari sırlar gibi entelektüel mülkiyet unsurlarının yanında yönetim felsefesi, bilgi sistemleri ve örgüt kültürü gibi üst yapı unsurları da önemli bir yer tutar (Yörük ve Erdem, 2008:399). Müşteri sermayesi ise, işletmenin 
müşteriler, tedarikçiler, rakipler, iş ortakları, hükümet gibi firma dışı ilişkilerinden kaynaklanan bilgi olarak tanımlanabilir (Inkinen, 2015:519). Aynı zamanda, bir örgütün iş dünyası ile olumlu etkileşimde bulunma ve servet yaratma potansiyelini artırmak üzere yapisal ve insan sermayesini büyütme yeteneğidir (Nazari ve Herremans, 2007:597).

Teknoloji sektörü, genel özellikleri itibariyle, büyük ölçüde yaratıcılık ve yenilikçilik gibi unsurlara dayalı olarak gelişmektedir. Bir fikrin veya soyut yaratıcılı̆̆ın, somut, ticari ürünlere dönüştürülmesi sürekli inovasyon gerektirmektedir; bu süreç ise yapısal sermaye ile insan sermayesini ön plana çıkarmaktadır. Aynı zamanda, teknoloji şirketlerinin pazarın ihtiyaçlarına uygun ürün ve hizmetler geliştirebilmeleri için tüketicileriyle yoğun bir şekilde etkileşimde olmaları gerekmektedir. Pazarlama faaliyetleriyle desteklenen müşteri sermayesi, firma imajını güçlendirmek ve müşterilerle ilişkilerini geliştirmek için teknoloji firmalarının yatırım yapmaları gereken diğer önemli bir alandır (Chang vd., 2013:1369).

Bilgi toplumuna dönüşüm sürecinde, karlarını yenilik ve bilgiye dayalı ürün ve hizmetlerden elde eden şirketlerin taşıdığı önem giderek artmaktadır (Kayalı vd., 2007:69). $\mathrm{Bu}$ firmaların gelecekteki gelişim senaryolarını tanımlayabilmeleri için entelektüel sermaye unsurlarını ne kadar etkin kullandıkları ve sahip oldukları bilgi varlıklarını gelire dönüştürebilme potansiyeli stratejik bir konu olarak karşımıza çıkmaktadır. Bu çalışmada, Borsa İstanbul'da işlem gören teknoloji sektörü firmalarının gelir ve kar yaratma sürecinde entelektüel sermaye etkinliğinin veri zarflama analizi ile değerlendirilmesi amaçlanmıştır. $\mathrm{Bu}$ amaç doğrultusunda, Giriş bölümünü takiben teknoloji sektöründe entelektüel sermaye etkinliğinin değerlendirilmesine yönelik bir literatür araştırmasına yer verilmiştir. Daha sonra, veri zarflama analizi (VZA) yöntemi ve entelektüel sermaye bileşenlerini temsilen kullanılan girdi ve çıktılar açıklanmış ve uygulama sonucunda elde edilen bulgular yorumlanmıştır.

\section{LITERATÜR}

Entelektüel sermaye ve bileşenlerinin firma performansı üzerindeki etkisi pek çok çalışmanın konusu olmuştur. Üretim işletmeleri (Öztürk ve Demirgüneş, 1997), İMKB şirketleri (Karacaer ve Aygün, 2009), Atina Borsası (Maditinos vd., 2011), Sürdürülebilirlik Endeksi işletmeleri (Dönmez ve Erol, 2016), imalat (Gürkan vd., 2015; Akpınar ve Akpınar, 2016); otelcilik (Sardo vd., 2018); havacılık (Odabaşoğlu, 2018) gibi farklı sektörler ve piyasaların ele alındığı araştırmaların sonucunda entelektüel sermaye bileşenlerinin firmaların finansal performansı üzerindeki olumlu etkileri konusunda büyük ölçüde fikir birliği sağlanmıştır.

Teknoloji gibi bilgi yoğun sektörler üzerinde yapılan çalışmalarda (Çalışır vd., 2010; Kendirli ve Konak, 2015; Kandil Göker, 2017), ele alınan şirketler uzmanlık gerektiren, yenilikçilik, yaratıcılık gibi farklılaşmış becerilere sahip olmak zorunda olduklarından (Çalışır vd., 2010) ve üretim süreçleri büyük ölçüde maddi olmayan kaynaklara dayalı olduğundan (Kandil Göker, 2017) finansal performansın belirleyici unsuru olarak insan sermayesi, yapısal sermaye ve müşteri sermayesi gibi unsurlar ön plana çıkmaktadır. İltaş ve Kaya (2018), 20092015 döneminde BİST teknoloji firmalarını ele alıkları çalışmada entelektüel sermaye yatırımlarının göstergesi olan Ar-Ge harcamaları, maddi olmayan duran varlıklar, Ar-Ge yoğunluğu ve hisse başına karın uzun dönemde eşbütünleşik olduğunu tespit etmişlerdir. Aytekin ve Özçalık (2018), Ar-Ge harcamaları ile finansal performans arasında pozitif yönde 
bir ilişkinin varlığını bulgulamışlardır. Öte yandan, Türkiye'de teknoloji sektöründe bazı entelektüel sermaye unsurları ile finansal performans göstergeleri arasında zayıf bir ilişkinin varlığını bulgulayan çalışmalara da rastlanmıştır. Kayalı vd. (2007), 2005 yılı verilerini kullanarak yaptıkları çalışmada entelektüel sermaye unsurları ile firma performans göstergeleri arasında istatistiksel olarak anlamlı bir sonuca ulaşamamışlardır ve Türkiye'de teknoloji firmalarının entelektüel sermaye unsurlarına yeterince önem vermediği yorumunu yapmışlardır. Demirhan ve Aracıoğlu (2017), çalışmalarında BIST-Teknoloji Endeksinde işlem gören işletmelerin maddi olmayan duran varlıklarının toplam varlıklara oranı ve Ar-Ge giderlerinin satış gelirlerine oranı değişkenleri ile temsil edilen inovatif faaliyetlerinin finansal performansları üzerindeki etkisini analiz etmişlerdir. 2013-2016 dönemini kapsayan çalışmada Ar-Ge giderleri ile aktif karlılığı ve piyasa değeri/defter değeri oranları ile orta düzeyde ve anlamlı korelasyon tespit edilmiş, ancak çalışma kapsamındaki firmaların maddi olmayan duran varlıklara yaptıkları yatırımların ele alınan dönem içerisinde bir bütün olarak finansal performansa yansımadığı sonucuna ulaşmışlardır.

Literatürde veri zarflama analizinin pek çok alanda etkinlik ölçümünde kullanıldığ görülmektedir. Veri zarflama analizi ile farklı sektör uygulamalarına paralel olarak teknoloji şirketleri de araştırmacıların ilgi odağı olmuştur. Chen ve Ali (2004), 1991-1997 dönemini ele aldıkları çalışmada Fortune Global 500'de yer alan bilişim şirketlerinin etkinliklerini VZA ile incelemişlerdir. Tektüfekçi (2010), kriz öncesi ve kriz (2007-2009) yıllarını kapsayan çalışmada İMKB'ye kayıtlı teknoloji şirketlerinin ele alınan dönem içerisinde genelde düşük etkinlik düzeylerine sahip oldukları ve verimli çalışmadıkları ortaya çıkmıştır. Özdağoğlu (2015), 2014 yılı verilerini kullanarak BİST teknoloji şirketlerinin etkinliklerini araştırmış ve farklı sonuçlar ortaya koymuştur. Uygurtürk ve Yıldız (2018), 2014-2016 dönemini kapsayan çalışmalarında ilk önce Borsa İstanbul'da kayıtlı 14 bilişim şirketinin etkinliklerini VZA ile belirlemişler, daha sonra işletmelerin finansal performans sıralamalarını Gri İlişkisel Analiz (GİA) yöntemiyle ortaya koymuşlardır. Çalışma sonucunda VZA yöntemi ile GİA yöntemleri arasında tutarlılık olduğu tespit edilmiştir. Sahoo (2016), 1999-2008 dönemi için Hindistan'da faaliyet gösteren 72 yazılım şirketinin etkinliklerini VZA kullanarak incelemiştir. Çalışmanın sonuçları, ele alınan dönemde yazılım şirketlerinin toplam teknik etkinliklerinin düşük olduğunu $(0,47)$, ortalama saf teknik etkinliklerinin 0,65 olarak gerçekleştiğini ve örneklemdeki şirketlerin girdilerinin yüzde 35'ini etkin kullanamadıklarını ortaya koymuştur.

Entelektüel sermaye etkinliğini ölçmede VZA kullanan ilk çalışmalardan biri Leitner vd. (2005) tarafindan yapılmıştır. Bu çalışmada yazarlar Avusturya üniversitelerinde entelektüel sermaye göstergelerini yorumlamak ve sınıflandırmak için VZA'nın elverişli bir metot olduğunu göstermişlerdir. Wu vd. (2006) Tayvan entegre devre sektörü firmalarının rekabet avantajı yaratmada entelektüel sermayenin etkisini VZA ile araştırmışlardır. 19992002 dönemini kapsayan çalışmanın sonucunda incelenen şirketlerin yaklaşık üçte birinin sahip oldukları entelektüel sermayeyi etkin kullandıkları tespit edilmiştir. Yalama ve Coşkun (2007), İMKB'ye kote bankaların 1995-2004 dönemi verilerini kullanarak VZA ile entelektüel sermayenin karlılığa etkisini araştırmışlardır. Çalışmanın sonucunda Türk bankacilık entelektüel sermayeyi karlılığa dönüştürme oranı ortalama 61,3 olarak tespit edilmiştir. Campisi ve Costa (2008), VZA kullanarak İtalya'da biyomedikal sektörü işletmelerinin entelektüel sermaye yatırımlarının firma performansına etkisini araştırmışlardır. 2002-2004 dönemini kapsayan çalışmanın sonucunda ilgili sektörde maddi olmayan duran varlıklara daha fazla yatırım yapan şirketlerin her zaman daha iyi performansa 
ulaşamadıklarını, ancak bilgi varlıklarını optimal şekilde yönettiklerinde bir neden - sonuç ilişkisinin varlığını tespit etmişlerdir. Lu vd. (2010), iki aşamalı VZA modeli kullanarak Tayvan çip tasarım firmalarının entelektüel sermaye yaratım süreci ve entelektüel sermaye etkinliklerini ele almışlardır. Elde edilen sonuçlar, çalışma kapsamındaki şirketlerin entelektüel sermayeyi değer yaratmada etkin kullandıklarını göstermiştir. Aynı sektör için yapılan diğer bir çalışmada, Yang ve Chen (2010) analiz kapsamındaki 62 firmadan 30'unun entelektüel sermaye yönetiminde etkin olduklarını tespit etmişlerdir. Çiçek ve Onat (2012), IMKB'de teknoloji ve bilişim sektöründe işlem gören 9 işletmenin inovasyon odaklı faaliyetlerinin firma performansına etkisini VZA kullanarak araştırmışlardır. Belirlenen kriterlere göre analiz kapsamındaki 9 şirketten 5'i etkin olarak belirlenmiştir. Kweh vd. (2013), Malezya'da halka açık teknoloji şirketlerinin entelektüel sermaye yönetimi etkinliklerini VZA kullanarak araştırmışlardır. Entelektüel sermaye bileşenlerinin (kullanılan sermaye, insan sermayesi ve yapısal sermaye) girdi olarak kullandıkları çalışmada teknoloji şirketlerinin en fazla insan sermayesi unsuruna yatırım yaptıkları tespit edilmiştir. Bununla beraber, çalışma kapsamındaki şirketlerin yüzde 80'i değer yaratmada etkin olamadıkları raporlanmıştır. Chang vd. (2013), 2005 yılı verilerinin kullanarak Tayvan'da faaliyet gösteren 21 dijital içerik üreticisi firmanın entelektüel sermaye unsurlarının operasyonel performansa etkisini araştırmışlardır. Çalışmanın sonuçları, insan sermayesi ile müşteri sermayesi unsurlarının şirketlerin etkinliklerinde en belirleyici rolü üstlendiğini ortaya koymuştur. Çıtak ve İltaş (2017) BİST Teknoloji işletmelerinin araştırma geliştirme yatırımlarının etkinliklerini VZA yöntemi ile araştırmışlardır. Elde edilen sonuçlar firmaların saf teknik etkinliklerinin göreli olarak yüksek olduğunu ortaya koymuştur.

Yapılan literatür araştırması sonucunda, yurtdışında entelektüel sermaye etkinliğinin VZA ile değerlendirildiği pek çok çalışma yapılmış olmasına rağmen, Türkiye'de sınırlı sayıda araştırma bulunmaktadır. Bundan hareketle, bu çalışmada, gelir ve kar yaratma süreçlerinin büyük ölçüde bilgi ve inovasyona dayalı olduğu teknoloji sektöründe, entelektüel sermaye unsurlarının VZA ile değerlendirilmesi, literatüre katkıda bulunacağ düşünülmektedir.

\section{VERİ ZARFLAMA ANALIZİ}

Veri Zarflama Analizi benzer yapıdaki karar verme birimlerinin (KVB) göreli etkinliklerini ölçmeyi amaçlayan doğrusal programlama tabanlı parametrik olmayan bir etkinlik ölçme yöntemidir. Bu yöntemin temelini oluşturan göreli etkinlik sadece analize konu olan birimlerin birbirileriyle ilişkili etkinlikleridir (Karacabey, 2001:4). Charnes vd. (1978) tarafindan geliştirilen (CCR modeli) ve daha sonra Banker vd. (1984) tarafindan BCC modeli ile genişletilen VZA, çoklu girdi ve çoklu çıktı ortamında analize imkan tanır. Doğrusal programlama sonucu göreli olarak etkin bulunan KVB'ler etkinlik sınırını oluştururlar; etkin olmayan karar birimleri ise etkin olan birimlere benzetilmeye çalış1larak her biri için bir referans kümesi ve hedef değerler belirlenir. "Girdi odaklı" ve "çıktı odaklı" olmak üzere iki ana gruba ayrılan VZA modellerinde, belirli bir çıktı düzeyinde minimum girdi kullanmak veya belirli bir girdi düzeyinde maksimum çıktı elde etmek amaçlanmaktadır (Savaş, 2015).

Girdi odaklı CCR modelinin matematiksel gösterimi aşağıdaki gibidir (Cooper vd.,2007:73; Behdioğlu ve Özcan, 2009: 306; Savaş, 2015:212):

$$
E_{k}=\min \theta-\varepsilon\left(\sum_{i=1}^{m} s_{i}^{-}+\sum_{r=1}^{s} s_{r}^{+}\right)
$$


Kisitlar ise,

$$
\begin{array}{ll}
\sum_{j=1}^{n} x_{i j} \lambda_{j}+s_{i}^{-}=\theta x_{i o} & \mathrm{i}=1,2,3, \ldots \ldots, \mathrm{m} \\
\sum_{j=1}^{n} y_{r j} \lambda_{j}-s_{i}^{+}=y_{r o} & \mathrm{r}=1,2,3, \ldots \ldots, \mathrm{s} \\
\lambda_{j}, s_{i}^{-}, s_{r}^{+} \geq 0 &
\end{array}
$$

Burada,

$$
\begin{array}{lc}
\text { m } & \text { : girdi sayısı } \\
\text { s } & \text { : çıktı sayısı } \\
\text { n } & \text { KVB sayısı } \\
\text { xij } & \text { : j. karar birimine ait i. girdi miktarı } \\
\text { yrj } & \text { : j. karar birimine ait r. çıktı miktarı } \\
\text { xio } & \text { : etkinliği ölçülen o. KVB'ye ait i. girdi miktarı } \\
\text { yro } & \text { : etkinliği ölçülen o. KVB'ye ait r. çıtı miktarı } \\
\text { sr+ } & \text { : eksik üretilen çıktılara ilişkin aylak değişken } \\
\text { si- } & \text { : fazla kullanılan girdilere ilişkin aylak değişken } \\
\varepsilon & \quad \text { : pozitif çok küçük bir sayı } \\
\lambda j & \text { : j’nci karar biriminin aldığı yoğunluk değeri } \\
\text { Ek } & \text { : etkinlik katsayısı }
\end{array}
$$

Etkin olmayan karar biriminin "referans kümesinde" bulunan karar birimlerinin oluşturduğu kuramsal birim aşağıdaki şekilde hesaplanmaktadır (Behdioğlu ve Özcan, 2009:306; Özden, 2008:172-173):

$$
\begin{array}{ll}
X^{K B}=\theta * X^{K}-s_{i}^{-} & \mathrm{i}=1,2, \ldots, \mathrm{m} \\
Y^{K B}=Y^{K}+s_{r}^{+} & \mathrm{r}=1,2, \ldots, \mathrm{s}
\end{array}
$$

Göreli etkin olmayan KVB'nin referans kümesindeki KVB'ler gibi etkin hale gelebilmesi için kuramsal KVB'nin girdi ve çıktı düzeylerini hedeflemesi gerekir. Hedef değerler ile gerçekleşen değerler arasındaki ilişkiden yararlanarak potansiyel iyileştirmeler yüzde olarak aşağıdaki formülle hesaplanabilir (Özden, 2008:173; Yalama ve Coşkun, 2007:261):

$$
\text { PI }(\text { Potansiyel İyileştirme })=(\text { Hedef-Gerçekleşen }) / \text { Gerçekleşen }
$$


Göreli etkin olmayan KVB'nin etkin hale gelebilmesi için, PI yüzdesi negatif çıkan değişken değeri PI oranında azaltılmalı, pozitif çıkan değişken değeri PI oranında artırılmalıdır. Eğer PI değeri sıfırsa, herhangi bir iyileştirme yapmaya gerek yoktur (Özden, 2008:173). Bu çalışmada kapsamında, bu oran örneklemdeki en iyi uygulamaya göre, etkin olmayan teknoloji şirketleri tarafından kullanılan entelektüel sermaye bileşenlerinin kara dönüştürülemeyen kısmı olarak ifade edilebilir (Yalama ve Coşkun, 2007:261).

CCR modeli ile elde edilen sonuç karar birimlerinin toplam teknik etkinlik (TE) katsayılarını göstermektedir. Bu modelde bir karar biriminin etkin olabilmesi için $\theta=1$ ve $\mathrm{s}^{-}$ $=\mathrm{s}_{\mathrm{i}}+=0$ koşullarının birlikte sağlanması gerekir. $\theta$ 'nin 1'den küçük bir değer alması durumunda işletmenin toplam teknik etkin olmadığ 1 söylenebilir. Ölçeğe göre sabit getiri varsayımı ile çalışan CCR modeline Banker vd. (1984) tarafından $\sum_{j=1}^{n} \lambda_{j}=1$ şeklinde ek bir konveksite kısıtı getirilerek modele ölçeğe göre değişken getiri özelliği kazandırılmıştır. Bu özellik sayesinde, önceki modele göre hesaplanan toplam teknik etkinlik değerlerinin ölçek farklılıklarından arındırılması sağlanarak etkinsizliğin işletmenin kendisinden (saf teknik etkinlik) mi yoksa bulunduğu elverişsiz koşullardan (ölçek etkinliği) mı kaynaklandığ 1 tespit edilebilmektedir (Karacabey, 2001: 5; Wu vd., 2006:535). BCC modeli olarak literatüre geçen bu modelin uygulanması sonucu bulunan etkinlik katsayısı "saf teknik etkinlik" (STE) olarak adlandırılır ve firma yönetiminin girdileri çıktılara dönüştürmede yeteneğini göstermektedir (Lu, 2010:549). Bir karar verme biriminin hem CCR modeli hem de BCR modeline göre etkinlik skoru \%100 olması işletmenin en verimli ölçek büyüklüğünde faaliyet gösterdiği anlamına gelmektedir. Eğer firma BCC etkin ise fakat CCR skoru 1'den düşük ise işletmenin ölçek büyüklüğü nedeniyle lokal olarak verimli bir şekilde çalışıyor ancak toplamsal olarak verimli olmadığı anlaşılır. Ölçek büyüklüğünün neden olduğu etkinlik farkı ise iki modelden elde edilen etkinliklerin oranlanması ile bulunabilecektir (Banker vd. 1984:1088; Karacabey, 2001:6):

$$
\text { Ölçek Etkinliği }(\widetilde{O} E)=\frac{T E_{C C R} \text { modeli }}{S T E_{B C C} \text { modeli }}
$$

BCC modeli işletmelerin faaliyet gösterdiği ölçeğin artan, azalan ya da sabit getiri özelliğinin belirlenmesine imkan tanımaktadır. Eğer TE = STE ise ölçek etkinliği 1'e eşittir ve firma ölçeğe göre sabit getiri bölgesinde faaliyet göstermektedir. Diğer taraftan TE $\neq$ STE ise oran 1'den küçüktür ve işletme ölçek bakımından etkin değildir ve firma ölçeğini büyüterek ya da küçülterek optimal ölçek büyüklügüüne ulaşabilir ve girdi tasarrufunda bulunabilir. $\mathrm{Bu}$ noktada, ölçek bakımından etkin olmayan firmanın $\sum_{j=1}^{n} \lambda_{j}<1$ olması ölçeğe göre artan getiri; $\sum_{j=1}^{n} \lambda_{j}>1$ olması ise ölçeğe göre azalan getiri özelliğine işaret etmektedir. Ölçeğe göre azalan getiri, ele alınan işletmelerin entelektüel sermaye bileşenlerindeki artışa göre daha az finansal performans sağladıklarını ifade etmektedir. Bu durumda, işletme ölçeğini küçülterek optimal büyüklüğe ulaşabilir. Ölçeğe göre artan getiri ise, işletmelerin entelektüel sermaye girdilerinde artışa göre daha fazla finansal performans artışı sağlayabildiklerini göstermektedir ve ölçek büyütülerek etkinlik sağlanabilmektedir (Chang vd., 2013:1371).

\section{4. ÇALIŞMANIN VERİ SETİ VE KAPSAMI}

Bu çalışma 2017 ve 2018 yıllarında payları Borsa İstanbul'da teknoloji endeksinde işlem gören işletmeleri kapsamaktadır. Aynı sektörde veya benzer faaliyetlerde bulunan işletmelerin analiz kapsamına alınması VZA için gerekli olan homojenlik kriterini 
sağlamaktadır (Kweh vd., 2013:313). Analizde kullanılan veriler Kamuyu Aydınlatma Platformunda (KAP) yayınlanan yıllık mali tablo, bağımsız denetim raporları ve yıllık faaliyet raporlarından derlenmiştir. Veri toplanmaya teknoloji endeksinde kote olan 15 işletme ile başlanmış, 1 işletmenin verisine ulaşılamadığından çalışma kapsamına 14 şirket dahil edilmiştir. Bu şirketler, Tablo 1'de yer almaktadır.

Tablo 1. Çalışma Kapsamına Alınan İşletmeler

\begin{tabular}{|c|c|c|}
\hline 1 & ALCTL & ALCATEL LUCENT TELETAŞ TELEKOMÜNIKKASYON A.Ş. \\
\hline 2 & ARENA & ARENA BİLGİSAYAR SANAYİ VE TİCARET A.Ş. \\
\hline 3 & ARMDA & ARMADA BİLGISSAYAR SİSTEMLERİ SANAYİ VE TİCARET A.Ş. \\
\hline 4 & ASELS & ASELSAN ELEKTRONIK SANAYİ VE TİCARET A.Ș. \\
\hline 5 & DGATE & DATAGATE BİLGISAYAR MALZEMELERİ TİCARET A.Ş. \\
\hline 6 & DESPC & DESPEC BİLGISAYAR PAZARLAMA VE TİCARET A.Ş. \\
\hline 7 & FONET & FONET BILLGİ TEKNOLOJILERİ A.Ş. \\
\hline 8 & INDES & İNDEKS BİLGİSAYAR SISTEMLERİ MÜHENDİSLİK SANAYİ VE TİCARET A.Ş. \\
\hline 9 & KAREL & KAREL ELEKTRONIK SANAYİ VE TİCARET A.Ş. \\
\hline 10 & KRONT & KRON TELEKOMÜNIKKASYON HIZZMETLERİ A.Ş. \\
\hline 11 & LINK & $\begin{array}{l}\text { LİNK BİLGISAYAR SİSTEMLERİ YAZILIMI VE DONANIMI SANAYİ VE } \\
\text { TİCARET A.Ş. }\end{array}$ \\
\hline 12 & LOGO & LOGO YAZILIM SANAYİ VE TİCARET A.Ș. \\
\hline 13 & NETAS & NETAȘ TELEKOMÜNIKKASYON A.Ş. \\
\hline 14 & PKART & $\begin{array}{l}\text { PLASTIKKART AKILLI KART İLETIŞìM SİSTEMLERİ SANAYİ VE TİCARET } \\
\text { A.Ş. }\end{array}$ \\
\hline
\end{tabular}

Kaynak: KAP (2019), https://www.kap.org.tr/tr/Sektorler, (Erişim Tarihi: 01.03.2019)

Veri zarflama analizinde KVB'lerinin göreli etkinlikleri seçilen girdi ve çıtılara göre belirlenmektedir. $\mathrm{Bu}$ nedenle, kullanılacak girdiler ve çıktılar özenle seçilmelidir (Savaş, 2015:206). Yapılan literatür araştırması sonucunda önceki çalışmalarda kullanılan bazı girdi ve çıktı değişkenleri Tablo 2'de özetlenmiştir (Wang ve Chang, 2005; Wu vd. 2006; Nazari ve Herremans, 2007; Yalama ve Coşkun, 2007; Yörük ve Erdem, 2008; Campisi ve Costa, 2008; Lu vd., 2010; Çiçek ve Onat, 2012; Chang vd., 2013; Kweh vd., 2013; Uygurtürk ve Y1ld1z, 2018):

Tablo 2. Entelektüel Sermaye Etkinliği Ölçümünde Kullanılan Girdi ve Çıktı Değişkenleri

\begin{tabular}{|c|c|}
\hline $\begin{array}{l}\text { Girdi } \\
\text { (Entelektüel Sermaye Bileșenleri) }\end{array}$ & $\begin{array}{l}\text { Çıktı } \\
\text { (Firma Performans Ölçütü) }\end{array}$ \\
\hline $\begin{array}{ll}\text { - } & \text { Personel sayısı } \\
\text { - } & \text { Personel giderleri } \\
\text { - } & \text { Ar-Ge harcamaları } \\
\text { - } & \text { Faaliyet giderleri } \\
\text { - } & \text { Maddi olmayan duran varlıklar } \\
\text { - } & \text { Patent sayıs1 } \\
\text { - } & \text { Ar-Ge çalışanı sayısı } \\
\text { - } & \text { Pazarlama giderleri } \\
\text { - } & \text { Value Added Intellectual Coefficient (VAIC) yöntemiyle } \\
& \text { hesaplanan insan sermayesi etkinliği, yapısal sermaye } \\
& \text { etkinliği ve kullanılan sermaye etkinliği }\end{array}$ & $\begin{array}{ll}\text { - } & \text { Satış geliri } \\
\text { - } & \text { Aktif karlılığı } \\
\text { - } & \text { Özsermaye karlılığı } \\
\text { - } & \text { PiyasaDeğeri/Defter } \\
& \text { oranı } \\
\text { - } & \text { Net dönem karı }\end{array}$ \\
\hline
\end{tabular}


$\mathrm{Bu}$ veriler 1şığında bu çalışmada kullanılacak girdi değişkenlerinin entelektüel sermayeyi yaratma, kullanma ve performansa dönüştürme çabalarını yansıtacak şekilde belirlenmiş ve firmanın finansal göstergeleri ile ilişkilendirilmiştir. Çalışmada kullanılan girdi-çıktı bileşimi Tablo 3'te gösterilmektedir:

Tablo 3. Çalışmada Kullanılan Girdi ve Çıktı Değişkenleri

\begin{tabular}{|c|c|c|}
\hline $\begin{array}{l}\text { Temsil edilen entelektüel } \\
\text { sermaye bileşeni }\end{array}$ & Girdi & Çıktı \\
\hline İnsan Sermayesi & Personel Sayısı & Dönem Karı \\
\hline Yapısal Sermaye & Maddi Olmayan Duran Varlıklar (MODV) & \multirow{2}{*}{ Satış Geliri } \\
\hline Müşteri Sermayesi & Pazarlama Giderleri & \\
\hline
\end{tabular}

Boussofiane, Dyson ve Thanassoulis (1991) karar verme birimi sayıs1 (n) ile girdi (m) ve çıktı (s) sayıları arasında $n \geq m+s+1$ şeklinde ifade edilen bir ilişki olması gerektiğine işaret etmişlerdir. Çalışmada kullanılan değişken sayısının bu şartı yerine getirdiği görülmektedir $(14 \geq 3+2+1)$. Girdi ve çıktı değişkenlerine ilişkin minimum, maksimum ve ortalama değerler Tablo 4'te gösterilmektedir;

Tablo 4. Girdi ve Çıktı Değişkenlerine İlişskin Minimum, Maksimum ve Ortalama Değerler

\begin{tabular}{|l|r|r|r|r|r|r|}
\hline \multirow{2}{*}{ Değişken } & \multicolumn{2}{|c|}{ Minimum } & \multicolumn{2}{c|}{ Maksimum } & \multicolumn{2}{c|}{ Ortalama } \\
\cline { 2 - 7 } & $2017 y l l ı$ & $2018 y l l$ & $2017 y l l$ & $2018 y l l$ & $2017 y l l$ & $2018 y l l$ \\
\hline Personel sayısı & 30 & 32 & 5.440 & 5.694 & 879 & 930 \\
\hline MODV (TL) & 142.295 & 91.396 & 868.997 .000 & 1.082 .067 .000 & 92.787 .239 & 119.319 .670 \\
\hline $\begin{array}{l}\text { Pazarlama } \\
\text { giderleri (TL) }\end{array}$ & 342.203 & 397.669 & 164.431 .000 & 150.760 .000 & 28.873 .215 & 31.744 .351 \\
\hline $\begin{array}{l}\text { Toplam } \\
\text { satıslar (TL) }\end{array}$ & 9.021 .876 & 11.527 .717 & 5.360 .279 .000 & 9.008 .516 .000 & 1.255 .818 .658 & 1.487 .158 .049 \\
\hline $\begin{array}{l}\text { Dönem karı } \\
\text { (TL) }\end{array}$ & 1.867 .467 & -19.814 .091 & 1.387 .849 .000 & 2.319 .347 .000 & 127.628 .940 & 190.544 .429 \\
\hline
\end{tabular}

İşletmelerin finansal tablolarından elde edilen verilerde negatif değer alanlar için VZA'nın değişkenlere ilişkin pozitif olma varsayımından hareketle aşağıdaki normalleştirme formülü ile pozitif değerlere dönüştürülmüştür (Budak, 2011; Yaşar ve Yavuz, 2017):

$$
\frac{Y_{r j}-Y_{j \min }}{Y_{j \max }-Y_{j \min }}
$$

$\mathrm{Bu}$ formülde Yrj, j. karar verme birimine ait çıktı değeri; Yjmin, en küçük r değeri, Yjmax, en büyük r değerini göstermektedir.

$\mathrm{Bu}$ çerçevede, teknoloji firmalarının entelektüel sermaye bileşenlerini finansal performansa dönüştürmede göreli etkinlikleri önce girdi odaklı CCR modeli ile toplam teknik etkinlikleri ölçülecektir. Ölçeğe göre sabit getiri varsayımı altında çalışan bu model yardımıyla göreli etkin firmalar belirlendikten sonra, etkin olmayan işletmeler için değişken getiri varsayımı altında çalışan girdi odaklı BCC modeli kullanılarak saf teknik etkinlik ve ölçek etkinliği katsayıları hesaplanacaktır. Daha sonra, BCC modeline göre etkin olmayan 
işletmeler için potansiyel iyileştirme oranları hesaplanarak entelektüel sermaye bileşenlerinin karlılığa dönüştürülemeyen kısım belirlenecektir.

\section{BULGULAR}

Ele alınan işletmelerde yöneticilerin girdi ve çıktılar üzerindeki kontrol gücü dikkate alınarak, girdi odaklı CCR ve BCC modelleri tercih edilmiştir. Önce sabit getiri varsayımı altında çalışan CCR modeli uygulanmış ve şirketlerin toplam teknik etkinlik değerleri hesaplanmıştır. Daha sonra, değişken getiri varsayımına dayalı BCC modeli uygulanmış ve işletmelerin saf teknik etkinlikleri ile ölçek etkinlikleri elde edilmiştir. Modellerin çözümünde DEA Frontier paket programı kullanılmıştır. Analiz sonucunda elde edilen etkinlik değerleri Tablo 5 'te gösterilmiştir.

Tablo 5. Çalışma Kapsamına Alınan Teknoloji Firmalarının 2017 ve 2018 yılları Toplam Teknik Etkinlik, Saf Teknik Etkinlik ve Ölçek Etkinliği Skorları

\begin{tabular}{|c|c|c|c|c|c|c|c|c|}
\hline \multirow[t]{3}{*}{ Şirket } & \multicolumn{2}{|c|}{$\begin{array}{c}\text { Toplam Teknik } \\
\text { Etkinlik }\end{array}$} & \multicolumn{2}{|c|}{ Saf Teknik Etkinlik } & \multicolumn{2}{|c|}{ Ölçek etkinliği } & \multicolumn{2}{|c|}{ Ölçeğe Göre getiri } \\
\hline & \multicolumn{2}{|c|}{ (CCR etkinliği) } & \multicolumn{2}{|c|}{ (BCC etkinliği) } & \multicolumn{2}{|c|}{ (ÖE) } & & \\
\hline & $2017 y l l v$ & $2018 y u l v$ & $2017 y u l l$ & 2018 yll & $2017 y u l l$ & $2018 y u l l$ & 2017 yll & $2018 y u l l$ \\
\hline ALCTL & 1,00000 & 1,00000 & 1,00000 & 1,00000 & 1,000 & 1,000 & Sabit & Sabit \\
\hline ARENA & 0,26906 & 0,47430 & 0,43302 & 0,86577 & 0,621 & 0,548 & Azalan & Azalan \\
\hline ARMDA & 1,00000 & 1,00000 & 1,00000 & 1,00000 & 1,000 & 1,000 & Sabit & Sabit \\
\hline ASELS & 1,00000 & 1,00000 & 1,00000 & 1,00000 & 1,000 & 1,000 & Sabit & Sabit \\
\hline DGATE & 1,00000 & 1,00000 & 1,00000 & 1,00000 & 1,000 & 1,000 & Sabit & Sabit \\
\hline DESPC & 0,32705 & 1,00000 & 1,00000 & 1,00000 & 0,327 & 1,000 & Artan & Sabit \\
\hline FONET & 0,53772 & 1,00000 & 1,00000 & 1,00000 & 0,538 & 1,000 & Artan & Sabit \\
\hline INDES & 0,89092 & 0,79983 & 1,00000 & 1,00000 & 0,891 & 0,800 & Azalan & Azalan \\
\hline KAREL & 0,18300 & 0,19724 & 0,18858 & 0,30233 & 0,970 & 0,652 & Azalan & Azalan \\
\hline KRONT & 0,26107 & 0,20625 & 0,64089 & 0,34409 & 0,407 & 0,599 & Artan & Artan \\
\hline LINK & 0,28104 & 1,00000 & 1,00000 & 1,00000 & 0,281 & 1,000 & Artan & Sabit \\
\hline LOGO & 0,13693 & 0,13804 & 0,14421 & 0,14136 & 0,950 & 0,977 & Artan & Azalan \\
\hline NETAS & 0,14330 & 0,12124 & 0,14754 & 0,15768 & 0,971 & 0,769 & Azalan & Azalan \\
\hline PKART & 1,00000 & 1,00000 & 1,00000 & 1,00000 & 1,000 & 1,000 & Sabit & Sabit \\
\hline Ortalama & 0,57358 & 0,70978 & $\mathbf{0 , 7 5 3 8 7}$ & 0,77223 & 0,783 & $\mathbf{0 , 8 8 2}$ & & \\
\hline
\end{tabular}

Tablo 5'teki sonuçlar incelendiğinde CCR modeline göre hesaplanan etkinlik değerleri bakımından 2017 yılında 14 işletme arasından 5 işletmenin (ALCTL, ARMDA, ASELS, DGATE, PKART) ele alınan girdi ve çıktı değerlerine göre etkinlik skorlarının 1 olduğu ve göreli toplam teknik etkinliğe ulaştığ görülmektedir. 2018 yılında toplam teknik etkin bulunan işletme sayısı 8 (ALCTL, ARMDA, ASELS, DGATE, DESPC, FONET, LINK, PKART) olmuştur. Diğer bir ifade ile bu işletmeler hem saf teknik etkinlik hem de ölçek bakımından optimal koşullarda faaliyet göstermektedirler. Bu işletmelerin, insan sermayesi, yapısal sermaye ve müşteri sermayesi gibi entelektüel sermaye bileşenlerini gelir ve kar elde etme sürecinde etkin kullandıkları söylenebilir. Analiz kapsamındaki işletmelerin 2017 yılı için ortalama CCR etkinliği 0,573 olarak hesaplanmış ve NETAS ve LOGO işletmelerinin sirasıyla 0,143 ve 0,136 etkinlik değerleriyle en düşük toplam teknik etkinliğe sahip oldukları görülmektedir. $\mathrm{Bu}$ ortalama, 2017 yılında teknoloji şirketlerinin entelektüel sermaye bileşenlerini gelir ve kar yaratmada yaklaşık olarak \%58 oranında etkin kullandıkları şeklinde 
yorumlanabilmektedir. 2018 yılında ise teknoloji işletmelerinin ortalama CCR etkinliği 0,710 olarak hesaplanmış ve NETAS ve LOGO işletmelerinin sırasıyla 0,121 ve 0,138 etkinlik değerleriyle en düşük toplam teknik etkinliğe sahip oldukları tespit edilmiştir. 2018 yılı CCR etkinlik ortalamasındaki artış çalışma kapsamındaki işletmelerin önceki yıla göre entelektüel sermaye kaynaklarını daha verimli kullandıklarını göstermektedir. $\mathrm{Bu}$ modele göre, etkinsizliğin nedeni saf teknik etkinlik olabileceği gibi, şirketin ideal ölçekte faaliyet göstermediğinden de kaynaklanabilir. Bu noktada, BCC modeli ölçek farkından arındırılmış saf teknik etkinlik skorlarını ortaya koymaktadır.

BCC modeline göre hesaplanan etkinlik değerleri incelendiğinde ele alınan 14 işletmeden 9'unun (ALCTL, ARMDA, ASELS, DGATE, DESPC, FONET, INDES, LINK, PKART) hem 2017 hem 2018 yılında etkin olduğu görülmektedir. Örneklemdeki 14 işletmenin 2017 yılı ortalama BCC etkinliği 0,753 olarak hesaplanmış ve en düşük BCC etkinliğine sahip şirketlerin NETAS $(0,147)$ ve LOGO $(0,144)$ olduğu tespit edilmiştir. 2018 yılında ortalama BCC etkinlik skoru artış göstererek 0,772 olarak hesaplanmıştır. Bu sonuç, çalışma kapsamındaki teknoloji işletmelerinin ölçek farklılıkları göz önünde bulundurulduğunda insan sermayesi, yapısal sermaye ve müşteri sermayesi bileşenlerini ortalama olarak 2017 y1lında $\% 75$ ve 2018 y1lında $\% 77$ oranında finansal başarı elde etmede etkin kullandıklarını ifade etmektedir.

Ölçek etkinliği skorları incelendiğinde 2017 yılında 5 firmanın (ALCTL, ARMDA, ASELS, DGATE, PKART) etkinlik değerlerinin 1 olduğu ve sabit getiri ölçeğinde faaliyet gösterdiği görülmektedir. Bu bulgu, işletmelerin çıktı değerlerinin, girdilerindeki artış ile aynı oranda arttığını göstermektedir. Analiz kapsamındaki işletmelerden 4'ü (ARENA, INDES, KAREL, NETAS) ölçeğe göre azalan getiri ile faaliyet göstermektedir; bu bulgu Türkiye'de teknoloji sektöründe rekabetin yoğunluğuna dair bir ipucu şeklinde yorumlanabilmektedir. Diğer 5 işletme (DESPC, FONET, KRONT, LINK, LOGO) ölçeğe göre artan getiri özelliği taşımaktadır; diğer bir ifade ile işletmelerin entelektüel sermaye girdilerinde artışa göre daha fazla finansal performans artışı sağladıklarını göstermektedir. Bu işletmeler incelendiğinde, 3'ünün BCC etkinlik skorlarının 1 olduğu görülmektedir; bu durum söz konusu işletmelerin göreli olarak entelektüel sermaye bileşenlerini gelir ve kar yaratmada etkin kullandıklarını ve ölçeklerini büyüterek tam etkinliğe ulaşabileceklerini göstermektedir. 2018 y1lında ise 8 işletmenin (ALCTL, ARMDA, ASELS, DGATE, DESPC, FONET, LINK, PKART) sabit getiri ölçeğine ulaştığı görülmektedir. Etkin olmayan işletmelerden 5'i azalan getiri ölçeğinde, 1 'i ise artan getiri ölçeğinde faaliyet gösterdiği anlaşılmaktadır.

Daha önce ifade edildiği gibi, veri zarflama analizinde etkin olmayan KVB'lerin etkin hale gelebilmeleri için etkin firmalar arasından bir referans kümesi oluşturulmaktadır. BCC modeline göre etkin olmayan işletmeler için referans alınan firmalar ve ağırlık oranları Tablo 6‘da gösterilmiştir: 
Tablo 6. 2017 ve 2018 Yıllarında BCC Etkin Olmayan İşletmeler İçin Referans Alınan Firmalar ve Ağırlıkları

\begin{tabular}{|c|c|c|c|c|c|}
\hline Yil & İşletmeler & Referans Alınan & rmalar (Referan & llkları $\lambda$ ) & \\
\hline \multirow[t]{5}{*}{2017} & ARENA & ARMDA $(0,319)$ & DGATE $(0,579)$ & INDES $(0,102)$ & \\
\hline & KAREL & ASELS $(0,015)$ & DGATE $(0,225)$ & PKART $(0,760)$ & \\
\hline & KRONT & DGATE $(0,118)$ & $\operatorname{DESPC}(0,279)$ & LINK $(0,603)$ & \\
\hline & LOGO & $\operatorname{ASELS}(0,019)$ & DGATE $(0,724)$ & FONET $(0,257)$ & \\
\hline & NETAS & ASELS $(0,017)$ & DGATE $(0,963)$ & PKART $(0,020)$ & \\
\hline \multirow[t]{5}{*}{2018} & ARENA & ARMDA $(0,773)$ & INDES $(0,227)$ & & \\
\hline & KAREL & $\operatorname{ALCTL}(0,119)$ & ASELS $(0,020)$ & INDES $(0,090)$ & PKART $(0,771)$ \\
\hline & KRONT & DESPC $(1,000)$ & & & \\
\hline & LOGO & ASELS $(0,021)$ & DESPC $(0,886)$ & LINK $(0,094)$ & \\
\hline & NETAS & DGATE $(0,907)$ & INDES $(0,093)$ & & \\
\hline
\end{tabular}

Tablo 6'daki sonuçlar incelendiğinde BCC modeline göre etkin olmayan firmaların etkin olabilmeleri için en iyi performans gösteren firmalar arasından 2017 yılında en fazla DGATE firmasının, 2018 yılında ise INDES ve DESPC firmalarının referans alındığ görülmektedir. Örneğin, 2017 verilerine göre ARENA firması teknik etkin olabilmek için girdi ve çıktı kombinasyonlarını parantez içinde verilen ağırlıklar $(\lambda)$ kadar ARMDA, DGATE ve INDES firmalarına benzeterek hedeflenen değerler hesaplanabilmektedir.

Çalışma kapsamında BCC etkin olmayan işletmeler için göreli hedef değerler belirlendikten sonra potansiyel iyileştirme oranları hesaplanarak girdilerinin ne kadar azaltmaları ve çıktılarının ne kadar artırmaları gerektiği tespit edilmiştir. Aynı zamanda, girdilerdeki fazlalık BİST teknoloji işletmelerinin insan sermayesi, yapısal sermaye ve müşteri sermayesi bileşenlerinin gelir ve kara dönüştürülemeyen kısmı olarak ortaya konulmuştur (Yalama ve Coşkun, 2007:263).

Tablo 7. 2017 ve 2018 Yıllarında BCC Etkin Olmayan İşletmeler için Potansiyel İyileştirme Oranları

\begin{tabular}{|c|l|l|l|l|l|l|}
\hline Yıl & İşletmeler & \multicolumn{3}{|c|}{ Girdi } & \multicolumn{2}{c|}{ Çıktı } \\
\cline { 3 - 7 } & & $\begin{array}{l}\text { Maddi Olmayan } \\
\text { Duran Varlıklar }\end{array}$ & $\begin{array}{l}\text { Personel } \\
\text { Sayısı }\end{array}$ & $\begin{array}{l}\text { Pazarlama } \\
\text { Giderleri }\end{array}$ & $\begin{array}{l}\text { Dönem } \\
\text { Karı }\end{array}$ & Hasılat \\
\hline \multirow{3}{*}{2017} & ARENA & $-0,57$ & $-0,57$ & $-0,62$ & 19,94 & 0,00 \\
\cline { 2 - 7 } & KAREL & $-0,81$ & $-0,87$ & $-0,81$ & 0 & 0,21 \\
\cline { 2 - 7 } & KRONT & $-0,80$ & $-0,36$ & $-0,36$ & 0 & 8,66 \\
\cline { 2 - 7 } & LOGO & $-0,87$ & $-0,86$ & $-0,86$ & 0 & 3,89 \\
\cline { 2 - 7 } & NETAS & $-0,85$ & $-0,94$ & $-0,85$ & 0 & 0,44 \\
\hline \multirow{3}{*}{2018} & ARENA & $-0,46$ & $-0,13$ & $-0,44$ & 1,43 & 0 \\
\cline { 2 - 7 } & KAREL & $-0,70$ & $-0,82$ & $-0,70$ & 0 & 0 \\
\cline { 2 - 7 } & KRONT & $-0,98$ & $-0,66$ & $-0,69$ & 0,67 & 9,31 \\
\cline { 2 - 7 } & LOGO & $-0,92$ & $-0,86$ & $-0,86$ & 0 & 0,54 \\
\cline { 2 - 7 } & NETAS & $-0,99$ & $-0,97$ & $-0,84$ & - & 0 \\
\hline
\end{tabular}

Tablo 7 incelendiğinde 2017 yılında etkin olmayan KAREL, KRONT, LOGO ve NETAS işletmelerinin örneklemdeki etkin bulunan işletmelere göre maddi olmayan duran varlıklarının \% 80-87'lik bir kısmını kar yaratmada etkin kullanamadıkları ortaya çıkmaktadır. Diğer bir ifadeyle, maddi olmayan duran varlıkların atıl kalan kısmı iyileştirme oranı kadar azaltılması gerekmektedir. Benzer şekilde, personel sayısına bakıldığında en fazla 
NETAŞ (\%94), KAREL (\%87) ve LOGO (\%86) işletmelerinde iyileştirmeye ihtiyaç olduğu görülmektedir. Pazarlama giderleri bakımından en fazla iyileştirmeye gereksinim duyan şirketler LOGO (\%86) ve NETAS'tır (\%85). 2018 y1lı potansiyel iyileştirme oranları KRONT, NETAŞ işletmelerinde maddi olmayan duran varlıkların göreli olarak \%99'a yakın bir kısmı etkin kullanamadıklarını ortaya koymaktadır. Genel olarak personel sayısı girdileri incelendiğinde en fazla iyileştirmeye ihtiyaç duyan şirketlerin NETAS ve LOGO olduğu, pazarlama giderleri ele alındığında ise NETAS, LOGO, KAREL ve KRONT işletmelerinin göreli olarak pazarlama giderlerinin büyük bir kısmı atıl kaldığını göstermektedir.

\section{SONUÇ}

Günümüz bilgi çağında, insan sermayesi, yapısal sermaye ve müşteri sermayesi bileşenlerinden oluşan entelektüel sermaye, işletmeler için rekabet avantajı sağlayan ana kaynaklardan biridir (Wu, 2006). Bu ortamda, özellikle teknoloji şirketlerinin entelektüel kaynaklarına yapacakları yatırımları, bu varlıkların etkin kullanımı ve sahip oldukları maddi olmayan sermayelerini finansal başarıya dönüştürmeleri stratejik önem taşır. Aynı zamanda, teknoloji sektörü işletmeleri için, iyi uygulamaları referans alarak, sahip oldukları kaynakları kıyaslama yoluyla geliştirme ve sürekli bir iyileştirme anlayışı kritik öneme sahiptir.

Bu çalışmada, 2017 ve 2018 yılında Türkiye'de teknoloji sektöründe faaliyet gösteren ve payları Borsa İstanbul'da işlem gören şirketlerin entelektüel sermaye bileşenlerinin etkinliği VZA ile değerlendirilmiştir. Literatüre bağlı kalarak yapısal sermaye, insan sermayesi ve müşteri sermayesi bileşenleriyle ilişkilendirilen maddi olmayan duran varlıklar, personel sayısı ve pazarlama giderleri analizde girdi olarak kullanılmış, dönem karı ile hasılat kalemleri finansal performans ölçüsü olarak çıktı değişkeni olarak belirlenmiştir. Analiz sonuçları, CCR modeline göre 2017 yılında 14 işletmeden 5'inin (ALCTL, ARMDA, ASELS, DGATE, PKART) ve 2018 yılında 8 firmanın (ALCTL, ARMDA, ASELS, DGATE, DESPG, FONET, LINK, PKART) sahip olduğu entelektüel sermaye kaynaklarını gelir ve kar yaratma sürecinde etkin kullandığını göstermektedir. İşletmelerin ölçeğinden kaynaklanan farklılıkları göz önünde bulunduran BCC modeline göre, çalışma kapsamındaki 14 işletmeden 9'u (ALCTL, ARMDA, ASELS, DGATE, DESPG, FONET, INDES, LINK, PKART) hem 2017 hem 2018 yıllarında etkin bulunmuş ve etkinlik skorlarının ortalaması sırasıly 0,75 ve 0,77 olarak tespit edilmiştir. Bu bulgu, Borsa İstanbul'da kote şirketlerin sahip oldukları insan sermayesi, yapısal sermaye ve müşteri sermayelerini 2017 yılında $\% 75$ ve 2018 yılında \%77 oranında finansal başarıya dönüştürdükleri şeklinde yorumlanabilir. Ölçek etkinliği sonuçlarına göre, 2017 yılında 5 işletme (ALCTL, ARMDA, ASELS, DGATE, PKART) sabit getiri ölçeğinde faaliyet gösterirken, 2018 yılında ideal ölçekte faaliyet gösteren işletme sayısı 8'e (ALCTL, ARMDA, ASELS, DGATE, DESPG, FONET, LINK, PKART) ulaşmıştır. Aynı zamanda, artan ve azalan getiri ölçeğinde faaliyet gösteren işletmeler tespit edilmiştir.

Sahip olunan kaynakların etkin kullanımı sonucunda, işletmelerin finansal göstergelerinde artış olacaktır; bu nedenle, etkin olmayan işletmeler hangi girdi ve çıktılarında değişiklik yapmaları gerektiğini bilmeleri ve benzerleri arasında en iyi uygulamaları örnek almaları büyük önem arz etmektedir. Çalışmanın sonuçları, en iyi performansı gösteren şirketler arasında DGATE'in (2017), INDES (2018) ve DESPC (2018) en fazla referans gösterildiğini ortaya koymaktadır. 
Çalışmanın sonuçları genel olarak değerlendirildiğinde, 2018 yılı etkinlik skorlarının bir önceki yıla göre artı̧̧ göstermesi, ortalama olarak teknoloji işletmelerinin sahip oldukları entelektüel sermaye varlıklarını daha etkin kullanıp daha fazla performans elde ettiklerini göstermektedir. Bununla beraber, entelektüel sermaye bileşenlerinin yaklaşık olarak \%23'lik kısmı atıl kaldığı ve finansal performansa dönüştürülemediğini göstermektedir. Bu noktada, etkin olmayan işletmelerin sahip oldukları insan sermayesi ve müşteri sermayesi aracılığıyla yapısal sermayelerinin potansiyelinin ortaya çıkarılması ve karlılığa dönüşmesi için yeni stratejiler geliştirmesi, bu işletmeleri sektör dinamikleri ile uyumlu hale getirecektir.

Bilindiği gibi, VZA belirli bir zaman dilimi içinde göreli etkinlik ölçümü için uygun bir yöntemdir, fakat mutlak etkinlik hakkında bilgi vermez (Savaş, 2015:209). Bu nedenle, araştırmanın sonuçları sadece ele alınan şirketlerle ile sınırlıdır; örnekleme farklı işletmelerin alınması veya çıkarılması durumunda sonuçların değişiklik göstereceği hususu göz önünde bulundurulmalıdır. Ayrıca, etkinlik ölçümü belirlenen girdi ve çıktılara göre gerçekleştirildiğinden, entelektüel sermaye bileşenleriyle ilişkilendirilen farklı girdilerin seçilmesi durumunda da sonuçlar farklılık gösterebilir.

Entelektüel sermaye kavramının şirketlerin finansal performansı için önemi göz önünde bulundurulduğunda, insan sermayesi, yapısal sermaye ve müşteri sermayesi bileşenlerinin performansı farklı sektörler ve farklı dönemler için ele alınması literatüre katkı sağlayacağ 1 düşünülmektedir.

\section{KAYNAKLAR}

Akpınar, Onur - Akpınar, Ali Talip (2016), "Entellektüel Sermaye Bileşenlerinin İşletme Değerine ve Performansına Etkisi: Türkiye'deki İmalat İşletmeleri Örneği”, Kastamonu Üniversitesi İktisadi ve İdari Bilimler Fakültesi Dergisi, 12, ss. 427-438.

Aytekin, Sinan - Özçalık, Sevinç Güler (2018), "Borsa İstanbul Teknoloji ve Bilişi̇im Endeksi Firmalarında Ar-Ge Harcamaları ve Finansal Performans İlişkisi”, Anemon Muş Alparslan Üniversitesi Sosyal Bilimler Dergisi, 6(ICEESS’ 18), ss. 67-73.

Banker, Rajiv D.- Charnes, Abraham - Cooper, William W. (1984), "Some Models for Estimating Technical and Scale Inefficiencies in Data Envelopment Analysis", Management Science, 30(9), pp. 1078-1092.

Behdioğlu, Sema - Özcan, Gözde (2009),"Veri Zarflama Analizi ve Bankacılık Sektöründe Bir Uygulama", Süleyman Demirel Üniversitesi İktisadi ve İdari Bilimler Fakültesi Dergisi, 14(3), ss. 301-326.

Bontis, Nick (1998), "Intellectual Capital: An Exploratory Study That Develops Measures and Models", Management Decision, 36(2), pp. 63-76.

Boussofiane, Aziz -Dyson, Robert G. - Thanassoulis, Emmanuel(1991), “Applied Data Envelopment Analysis", Europen Journal of Operational Research, 52(1), pp. 1-15.

Budak, Hüseyin (2011), “Veri Zarflama Analizi ve Türk Bankacılık Sektöründe Uygulaması”, Marmara Üniversitesi Fen Bilimleri Dergisi, 23(3), ss. 95-110. 
Campisi, Domenico -Costa, Roberta (2008), “A DEA-Based Method to Enhance Intellectual Capital Management”, Knowledge and Process Management, 15(3), pp. 170-183.

Chang, Chia-Chin - Hung,Shiu-Wan -Huang, Sin-Yi (2013), "Evaluating the Operational Performance of Knowledge-BasedIndustries: the Perspective of Intellectual Capital", Quality and Quantity, 47, pp. 1367-1383.

Charnes, Abraham - Cooper, William W. - Rhodes, Edwardo (1978), "Measuring the Efficiency of Decision Making Units", European Journal of Operations Research, 2, pp. 429-444.

Chen, Yao - Ali, Agha Iqbal (2004), "DEA Malmquist Productivity Measure: New Insights With an Application to Computer Industry", European Journal of Operational Research, 159(1), pp. 239-249.

Cooper, William W.-Seiford, Lawrence M. - Tone, Kaoru (2007), "Data Envelopment Analysis: A Comprehensive Text with Models, Application, Reference sand DEASolver Software", Second Edition, Springer Science, New York.

Çalışır, Fethi -Gumuşsoy, Ciğdem Altın - Bayraktaroğlu, A. Elvan - Deniz, Ece (2010), "Intellectual Capital in the Quoted Turkish ITC Sector,Journal of Intellectual Capital, 11(4), pp. 537-553.

Çıtak, Levent - İltaş, Yüksel (2017), “Ar-Ge Yatırımlarının Finansal Performans Üzerindeki Etkisi ve Bist Teknoloji Endeksi Firmalarının Etkinliklerinin Değerlendirilmesi”, Muhasebe ve Finansman Dergisi, 76, ss.239-254.

Çiçek, Hüseyin- Onat, Osman K. (2012) "İnovasyon Odaklı Faaliyetlerin Firma Performansına Etkisinin Veri Zarflama Analizi ile Belirlenmesi; İMKB Üzerine Bir Araştırma”, Mehmet Akif Ersoy Üniversitesi Sosyal Bilimler Enstitüsü Dergisi, 4(7), ss. 46-53.

Demirhan, Dilek -Aracıoğlu, Burcu (2017), "İnovasyon ve Finansal Performans Arasındaki İlişki: BİST Teknoloji Endeksindeki Firmalar Üzerine Bir Araştırma”, Uluslararası İktisadi ve İdari İncelemeler Dergisi, 16(UİK Özel Sayıs1), ss.195-218.

Dönmez, Adnan- Erol, İbrahim (2016), "Entelektüel Sermayenin Ölçülmesi: VAİCTM Yöntemi Yardımıyla BİST-Sürdürülebilirlik Endeksi İşletmeleri Üzerine Bir Uygulama", Mali Çözüm, 138, ss. 27-56.

Edvinsson, Leif -Malone, Michael S. (1997), “Intellectual Capital: Realizing Your Company’s True Value by Finding Its Hidden Roots”, New York, Harper Business.

Edvinsson, Leif - Sullivan, Patrick (1996), "Developing a Model For Managing Intellectual Capital”, European Management Journal,14(4), pp. 356-364.

Gürkan, Serhan -Gökbulut Rasim İlker - Çolak, Nurdan (2015), "Entelektüel Katma Değer Katsayısı Bileşenlerinin İşletmelerin Finansal Performansı Üzerindeki Etkisi”, Ekonomik ve Sosyal Araştırmalar Dergisi, 11(2), ss. 45-64. 
Inkinen, Henri (2015), "Review of Empirical Researchon Intellectual Capital and Firm Performance", Journal of Intellectual Capital, 16(3), pp. 518-565.

İltaş, Yüksel - Kaya, H. Pınar (2018), “Ar-Ge Harcamalarının Hisse Başına Kara Etkisi: BİST Teknoloji Endeksi (Xutek) Firmaları Üzerine Bir Uygulama”, Cumhuriyet Üniversitesi İktisadi ve İdari Bilimler Dergisi, Cilt 19(1), ss. 149-162.

Kandil Göker, İlkut Elif (2017), "Bilişim Sektöründe Entelektüel Sermaye ile Finansal Performans Ilişkisinin Belirlenmesine Yönelik Bir Araştırma", 3(14), ss. 78-86.

Karacabey, Ali Argun (2001), “Veri Zarflama Analizi”, Ankara Üniversitesi Siyasal Bilgiler Fakültesi Tartışma Metinleri,33, ss. 1-4.

Karacaer, Semra - Aygün, Mehmet (2009), "Entellektüel Sermayenin Firma Performans1 Üzerindeki Etkisi”, Hacettepe Üniversitesi İktisadi ve İdari Bilimler Fakültesi Dergisi, 27(2), ss. 127-140.

Kayalı, Cevdet - Yereli, Ayşe N. - Ada, Şebnem (2007), "Entelektüel Katma Değer Katsayıs1 Yöntemi Kullanılarak Entelektüel Sermayenin Firma Değeri Üzerindeki Etkisinin Belirlenmesine Yönelik Bir Araştırma", Yönetim ve Ekonomi 14(1), ss. 67-90.

Kendirli, Selçuk - Konak, Fatih (2015), "Entelektüel Sermayenin Ölçülmesi ve Firma Performansı Üzerinde Etkisi: Borsa İstanbul'da İşlem Gören Bilişim Şirketleri Üzerine Bir Uygulama", Sakarya İktisat Dergisi, 4, ss. 31-51.

Kweh, QianLong - Chan, YeeChuann - Ting,Irene W. K. (2013), "Measuring Intellectual Capital Efficiency in The Malaysian Software Sector", Journal of Intellectual Capital, 14(2), pp. 310-324.

Leitner, Karl-Heinz -Schaffhauser-Linzatti, Michaela -Stowasser, Rainer - Wagner, Karin (2005), "Data Envelopment Analysis As Method For Evaluating Intellectual Capital", Journal of Intellectual Capital, 6(4), pp. 528-543.

Lu, Wen-Min -Wang, Wei-Kang -Tung, Wei-Ting - Lin, Fengyi (2010), "Capability and Efficiency of Intellectual Capital: The Case of Fabless Companies in Taiwan", Expert Systems with Applications, 37(1), pp. 546-555.

Maditinos, Dimitros -Chatzoudes, Dimitros -Tsairidis, Charalampos - Theriou, Georgios (2011), "The Impact Of Intellectual Capital On Firms' Market Value and Financial Performance", Journal of Intellectual Capital, 12(1), pp.132-151.

McGregor, Judy -Tweed, David - Pech, Richard (2004), "Human Capital in The New Economy: Devil's Bargain?", Journal of Intellectual Capital, 5(1), pp.153-164.

Nazari, Jamal A. -Herremans, Irene M. (2007), "Extended VAIC model: Measuring Intellectual Capital Components", Journal of Intellectual Capital, 8(4), pp. 595-609. 
Odabaşoğlu, Şener (2018), “The Effect of Intellectual Capital on Financial Performance in the Context of Airline Companies “, International Journal of Social Science Research 7(2), ss. 211-237.

OECD (1999), "Guidelines and Instructions for OECD Symposium", International Symposium Measuring Reporting Intellectual Capital: Experiences, Issues, and Prospects, Amsterdam.

Özdağoğlu, Aşkın (2015), "Bilişim Sektöründeki Şirketlerin Etkinliklerinin Veri Zarflama Analizi ile Değerlendirilmesi”, Yönetim ve Ekonomi, 22(2), ss. 331-340.

Özden, Ünal H. (2008), "Veri Zarflama Analizi (VZA) ile Türkiye'deki Vakıf Üniversitelerinin Etkinliğinin Ölçülmesi”, İstanbul Üniversitesi İşletme Fakültesi Dergisi 37(2), ss. 167-185.

Öztürk, M. Başaran-Demirgüneş, Kartal (2007), "Entelektüel Sermayenin Firma Değeri Üzerindeki Etkisinin Entelektüel Katma Değer Katsayısı Yöntemi ile Tespiti: Hisse Senetleri İMKB'de İşlem Gören Üretim Firmaları Üzerine Ampirik Bir Çalışma”, İMKB Dergisi, 10(37), ss. 59-80. ᄀ

Sahoo, Bimal Kishore (2016), "Ownership, Size, and Efficiency: Evidence From Software Companies in India", Benchmarking: An International Journal, 23(2), pp. 313-328.

Sardo, Felipe -Serrasquiero, Zelia - Alvez, Helena (2018), “On The Relationship Between Intellectual Capital and Financial Performance: A Panel Data Analysis on SME Hotels", International Journal of Hospitality Management, 75, pp. 67-74.

Savaş, Filiz (2015), "Veri Zarflama Analizi”, İşletmeciler, Mühendisler ve Yöneticiler İçin Operasyonel, Yönetsel ve Stratejik Problemlerin Çözümünde Çok Kriterli Karar Verme Yöntemleri, Editörler: Bahadır Fatih Yıldırım ve Emrah Önder, Bursa, Dora Basım-Yayın Dağıtım Ltd. Şti..

Stewart, Thomas A. (1997), "Intellectual Capital: The New Wealth of Organizations", Doubleday, New York.

Tektüfekçi, Fatma (2010), “IMKKB’ye Kayıtlı Halka Açık Teknoloji Şirketlerinde Finansal Etkinliğin Veri Zarflama Analizi (VZA) ile Değerlendirilmesi”, Organizasyon ve Yönetim Bilimleri Dergisi, 2(2), ss. 69-77.

Uygurtürk, Hasan - Yıldız, İlker (2018), "Borsa İstanbul'da Bilişim Sektöründe Faaliyet Gösteren İşletmelerin Etkinlikleri ile Finansal Performansları Arasındaki İlişkinin Belirlenmesi”, 22. Finans Sempozyumu Bildiriler Kitab1, ss.181-192.

Wang, Wen-Ying - Chang, Chingfu(2005), "Intellectual Capital and Performance in Causal Models: Evidence FromThe Information Technology Industry in Taiwan", Journal of Intellectual Capital, 6(2), pp. 222-236. 
Wu, Wann-Yih - Tsai, Hsin-Ju -Cheng, KueiYang -Lai, Mengkuan (2006), “Assessment of Intellectual Capital Management in Taiwanese IC Design Companies: Using DEA and the Malmquist Productivity Index”, R\&D Management, 36(5), pp. 531-545.

Yalama, Abdullah - Coşkun, Metin (2007), "Intellectual Capital Performance of Quoted Banks on the Istanbul Stock Exchange Market", Journal of Intellectual Capital, 8(2), pp. 256-271.

Yang, Chyan-Chen, Ta-Yuan (2010), "Evaluating the Efficiency Of Intellectual Capital Management for Taiwan IC Design Industry", African Journal of Business Management, 4(15), pp. 3366-3373.

Yaşar, Feyzi - Yavuz, Selahattin (2017), “İmalat İşletmelerinde Etkinlik Ölçümü: BİST 100 Örneği”, Bingöl Üniversitesi Sosyal Bilimler Enstitüsü Dergisi, 7, ss. 193-219.

Yörük, Nevin - Erdem, Meziyet S. (2008) 'Entelektüel Sermaye ve Unsurlarının, İMKB'de İşlem Gören Otomotiv Sektörü Firmalarının Finansal Performansı Üzerine Etkisi, Atatürk Üniversitesi İİBF Dergisi, 22(2), ss. 397-413. 